\title{
Impact of landscapes Dynamics and Intensity on Ecological Land in Major Ethiopia Cities
}

Mekonnen amberber Degefu ( $\nabla$ gmekonnena@gmail.com )

Kotebe Metropolitan University

\section{Research Article}

Keywords: ecological land, landscape transitions, cities resilience, sustainable development

Posted Date: March 2nd, 2021

DOI: https://doi.org/10.21203/rs.3.rs-249267/v1

License: (c) (i) This work is licensed under a Creative Commons Attribution 4.0 International License. Read Full License 

Ethiopia cities

3

4

5

6

7

8

9

10

11

12

13

14

15

16

17

Mekonnen Amberber 1, 2, *

1 Kotebe Metropolitan University, ${ }^{2}$ Addis Ababa University, center for environmental science gmekonnena@gmail.com

(7)

8

10

1

2



cities

\section{Abstract}

Background: Understanding the dependence of ecological land to dynamics of human-naturecoupled landscape is crucial for urban ecosystem resilience. The aim of present study is, explored and compared the spaciotemporal responses of ecological land to urban landscape dynamics in Bahir Dar, Addis Ababa, Adama and Hawassa cities for the last three decades (1990-2020). Three sets of Landsat satellite images from 1990 to 2020 and four urban land indexes were used to produce landscape maps and geospatial data analysis.

Result: The result analysis showed the substantial expansion in built up ecosystem which was manifested at the cost of ecological land. The built-up ecosystem totaled 17,491.2ha in 1990, which augmented to 42,298ha (141.8\%) in 2020 with an average annual growth rate of $33.73 \%$. A total of $40.97 \%$ of the prolonged built-up area was obtained from urban agricultural land alone. Moreover, urban sprawl is likely to continue, which will be outweighed by the loss of open space ecosystem. Besides, land use intensity (LUI) of each city in the years 1990 - 2020 were Addis Ababa (3.31), Hawassa (4.82), Adama (5.04), and Bahir Dar (3.56). Moreover, Integrated land use dynamics degree (ILUDD) was for Addis Ababa (1.7\%), Bahir Dar (4.17\%), Adama (2.25\%) and Hawassa (4.83\%). This confirmed that the spatial distribution LUI was significant consistency with ILUDD in all cities.

Conclusions: LUI dynamics pattern was followed "urban ecological land to multi-complex human-dominance ecosystem, with a significant influence on urban greenery and ecosystem services provides. Thus, in all cities, the implementation of effective ecological land management and urban planning policies are required for ensure economic development and ecosystem resilience.

Keywords: ecological land, landscape transitions, cities resilience, sustainable development 


\section{Introduction}

47

48

49

50

51

52

53

54

55

56

57

58

59

60

61

62

63

64

65

66

67

68
Urbanization and associated massive landscape change has led a substantial change on the quantity composition, structure, and function of ecological land (Liu et al., 2020a; Talukdar et al., 2020; Wangai et al., 2019) while, boosted the formation of human-dominated or human-nature-coupled ecosystems (Chen et al., 2021; Hu et al., 2019; Zhang et al., 2013; Zhang et al., 2018). During the past decades, most cities have experienced remarkable urban-rural expansion, mainly due to population growth and migration from rural to urban areas. According to Ye et al. (2018) the number of people living in cities is going up a fast rate from 0.75 billion (29.6\%) in 1950 to 6.34 billion (66.7\%) projected by 2050 and demand 1.2 million $\mathrm{km}^{2}$ cityscapes by 2030 (Das and Das, 2019; Seto et al., 2012). Thus, these urbanization scenarios and its inference to ecological land dynamics particularly in rapidly developing cities and surrounding ecosystems are becoming as a common issue in policy discussions and scientific analysis (Ha et al., 2020; Mekasha et al., 2020).

In view of, accelerated urban agglomeration in megacities poses huge opportunities and objections for the sustainable development of a countries. For example, megacities become the hubs of technology and business activity while, generate a significant amount of urban metabolic waste and required more scientific and technology based resilient infrastructures and land management strategies than emerging cities. On the other hand, urbanization in the developing world depends on conversion of ecological land to unstainable urban fabric ecosystems. Later, created policy and institutional, socioeconomical, environmental, and technological related challenges (Ahmed et al., 2015; Gashaw et al., 2018; Kindu et al., 2015). Moreover, urbanization and land competition in major cities (Addis Ababa, Adama, Mekella, Bahir Dar, and Hawassa) and other emerging cities 
of Ethiopia followed similar scenario and will continue for the next few decades due to their

70 uncontrolled fast-growing nature (Bulti and Abebe, 2020; Terfa et al., 2019; Wubie et al., 2020).

71 In contrast, ecological lands (urban forest and greenery water bodies) are being converted to

72 impervious surface and residential, industrial, and commercial systems. Generally, rapid sprawl

73 has created social, economic, and political instabilities that can be attributed to governance and

74 land use policy issues (Bhat et al., 2017; Das and Angadi, 2020; Mohamed and Worku, 2019; Zou

75 and Wang, 2021).

76 Land dynamic studies are not new issues for Ethiopia. However, studies are mostly spatially

77 limited and concentrated on specific ecosystem and land use types. For example, central highland

78 and forest ecosystem (Kindu et al., 2015, 2016; Minta et al., 2018; Yohannes et al., 2020), Northern

79 highlands (Gebrehiwot et al., 2020; Mekasha et al., 2020; Mekuriaw et al., 2020; Temesgen et al.,

80 2018; Tolessa et al., 2017) and single city based (Bulti and Abebe, 2020; Gashu and Gebre-

81 Egziabher, 2018; Kinfu et al., 2019; Larsen et al., 2019; Terfa et al., 2019). Although, LULC

82 dynamics and management vary significantly over time and from ecosystems to ecosystem. In

83 contrast, the present study focused the dynamics in the human - ecological land nexus at different

84 spatial and temporal scales of major active cities of Ethiopia have not studied before in holistic

85 approach. Consequently, the aim of this study is to appraise the spatial patterns of deviations in

86 ecological land and urban ecosystem, and to evaluate to what degree the existing ecological land

87 intervention processes and managemental approaches are effective in combating and controlling

88 unsustainable dynamics in cities of Ethiopia for implication of urban ecological land resilience. 


\section{Material and Methods}

90

91

92

93

94

95

96

97

98

99

100

101

102

103

104

105

106

107

108

109

\subsection{Study area}

This study was conducted in Addis Ababa, Hawassa, Adama, and Bahir Dar cities that have a high level of urban expansion, industrialization, and socioeconomic development in Ethiopia (Figure 1 and Table 1). Additionally, the cities were chosen for the study in order to maximize the probability of detecting changes in ecological landscapes due to urban sprawl. The size of four cities comprising the study total area was 102761.3ha.

\subsection{Satellite data acquisition and preparation}

In this study, three decades' time-series LULC change maps for each city were prepared by utilized multispectral Landsat imagery (Landsat TM, ETM+, and land OLI), which were retrieved on four distinct dates: 1990, 2000, 2010, and 2020 (Table 2). The images were taken in the dry season to reduce the impact of the cloud on the result. The radiometric correction, geometrical correction, and atmospheric correction of the images were done using the ERDAS 14 software. Later, a supervised (maximum likelihood algorithms) image classification technique was used for LULC classification. More than 50 spectral signatures have been taken as a typical signature for each LULC type, which has been acquired using a GPS device; Google Earth was applied for validation of the LULC type. The number of GCPs for each class was assigned by area proportion of the land uses. The LULC map of each city were categorized into five classes: urban forest and greenery, urban agriculture, urban built, bare, and water (Table 3). The LULC change detection was carried out using spatial automatic overlay analysis and the Zonal Tabulate Area function in ArcGIS version 10.4 to generate the Markov chain transition matrix of the study area. Then, the post- 
110 classification process was executed by recoding, majority filtering, clumping, elimination, and 111 mosaicking of the classified maps to reduce errors in the produced maps.

112 The overall producer's accuracy of LULC maps over the study period of each city (AA, AD, BD, 113 and HW) was $88.03 \%, 89.48 \%, 82.80 \%$, and 85.2 respectively; overall user's accuracy of LULC 114 maps over the study period was $88.10 \%, 89.13 \%, 82.63 \%$ and $87 \%$ for cities AA, AD, BD, and 115 HW in that order; the Kappa statistics of each city was 0.84 (AA), 0.86 (AD), 0.78 (BD) and $1160.87(\mathrm{HW})$ respectively. The overall accuracy of the LULC change dataset was $86.71 \%$ according 117 to field survey data and records. This result is aligning with the recommended value of many 118 scholars (Ha et al., 2020; Li et al., 2019).

119 To evidently reveal the spatial relations between LULC change and response for anthropogenic 120 sustainability in urban ecosystem nexus, we first compute LULC dynamics rate for a specific and 121 integrated LULC transformation of each city and cityscape level from 1990 to 2020 period, using 122 three effective parameters: land use dynamic degree (single land use dynamic degree (SLUDD), 123 integrated land use dynamic degree (ILUDD)), land use intensity (LUI) and land use diversity 124 (LUD) methods (Chen et al., 2019; Hu et al., 2019; Huang et al., 2019; Liu et al., 2020b; Shao et 125 al., 2020; Song and Deng, 2017; Zorrilla-Miras et al., 2014) followed equation 1 to 4. SLUDD 126 reveals the change rate of a single land use type, while ILUDD estimates the overall situation of 127 land use change rate. Besides, Land use intensity (LUI) is revealing the breadth and depth of land 128 use, which can be determined as a reply to the material and energy flows between natural and 129 human ecosystems and can be used to evaluate the intensity of the adaptations of a land use system 130 to the changing physical and socioeconomic circumstances (Chen et al., 2020; Zorrilla-Miras et 131 al., 2014). According to Chen et al. (2019) the intensity of interaction divided in to four ('open 132 space / bare land, was assigned the weighted value of 1, whereas urban built land was gives the 
133 weighted value 4. Urban Forest and greenery land and water areas, were given the weighted value 134 2, while urban agriculture land was assigned the weighted value of 3) based on the equilibrium 135 states of physical and socioeconomic influences on the land use systems. Furthermore, land use 136 diversity (LUD) represents LULC dynamics in relations to the structure, richness, and complexity 137 of different land use types.

$S L U D D=\frac{L A_{i, t 2}-L A_{i, t 1}}{L A_{i, t 1}} * \frac{1}{T} * 100 \%$

$I L U D D=\left(\sum_{i=1}^{n} \Delta L A_{i-j} \mid \sum_{i=1}^{n} L A_{(i, t 1)}\right) * \frac{1}{T} * 100 \%$

$L U I=\sum_{i=1}^{4} \frac{L A_{(i, t)}}{\sum_{i=1}^{n} L A_{(i, t)}} * D_{i}$

$L U D=-\sum_{i=1}^{n} \frac{L A_{(i, t)}}{\sum_{i=1}^{n} L A_{(i, t)}} * \ln \left(\frac{L A_{(i, t)}}{\sum_{i=1}^{n} L A_{(i, t)}}\right)$

142 Where $\mathrm{LA}_{(\mathrm{i}, \mathrm{t} 1)}$ and $\mathrm{LA}_{(\mathrm{i}, \mathrm{t} 2)}$ characterize the area of land use type $\mathrm{i}$ at time $\mathrm{t}_{1}$ and $\mathrm{t}_{2}$, respectively.

$143 \Delta \mathrm{LA}_{\mathrm{i}-\mathrm{j}}$ is the area of land use type $\mathrm{i}$ transformed to land use type $\mathrm{j}(\mathrm{j}=1,2, \mathrm{n}, \mathrm{i} \neq \mathrm{j})$ during the study 144 period, $\mathrm{n}$ is the number of land use types in the study area, $\mathrm{T}$ is the study period, and $\mathrm{D}_{\mathrm{i}}$ is the 145 weighted value of each land use type mentioned previously.

146 Furthermore, to measure annual urban expansion, we chose and calculated two indexes-Annual 147 Increase (AI) and Annual Growth Rate (AGR) of urban land (Meng et al., 2020; Wu, 2013; Zhao 148 and Fan, 2020). Annual increase (AI) is efficient to compare the expansion rates for the same city 149 among different periods, while annual growth rate (AGR) is more suitable for comparison among 150 different cities (Meng et al., 2020). Indexes used to quantify the urban growth rates are defined 151 using equation 9 and 10.

$152 A L=\frac{A_{\text {end }}-A_{\text {start }}}{d}$

$$
A G R=100 \% *\left[\left(\frac{A_{\text {end }}}{A_{\text {start }}}\right)^{\frac{1}{d}}-1\right]
$$


153 Where $\mathrm{A}_{\text {start }}$ and $\mathrm{A}_{\text {end }}$ are the areas of urban land at the initial and end time, respectively, and $\mathrm{d}$ (in 154 years) is defined as the time span of study period (Figure 2).

\section{3. Results}

\subsection{Land use, land cover dynamics during 1990 - 2020 cities}

157 The spatio-temporal land use dynamics degree of each city with the corresponding proportion is 158 illustrated in Table 3 - 7 and Figure 3. According to our LULC dynamics analysis, a substantial 159 amount of urban ecosystem converted to build up (residential) ecosystem from 1990 to 2020, 160 which was characterized by a net upsurge in building up and a large reduced of urban agriculture

161 and bare land (open space) ecosystem (Figure $4 \& 5$ ). In general, the total built-up ecosystem was 162 boosted by 24807.13 ha (141.8\%) in the study period. Whereas, urban agricultural ecosystem was 163 reduced by 7353.8 ha $(13.63 \%)$. Besides, urban forest and greenery ecosystems grow from 164 20345.49ha in 1990 to 20916 ha $(2.8 \%$ ) in 2020 , due to the climate-resilient green economy 165 (CRGE) strategies of the cities. On the other hand, the bare land (open space) ecosystem declined 166 by $7.75 \%, 20.6 \%$ for $1990-2000$, and 2000-2010 separately and generally dropped by $62.65 \%$ and 167 significant portion it transformed to build up land-use type and its dynamic degree was $20.79 \%$ 168 (Table 3). Overall, the bare land category looked to decline and 8732.24ha of areas was changed 169 to build up (residential) during 30 years of our assessment. Furthermore, the annual conversion 170 rate of bare land was 3.28\% per year from the 1990 to 2020 period, but the conversion rate was 171 dramatically accelerated by $6.74 \%$ per year from 2010 to 2020.

172 In 1990, the urban agricultural ecosystem was accounted for about a half portion of the total areas 173 of cities (45,572.82 ha) whereas, urban forest and greenery, built-up and, bare (open) land were 
174 covered 17,491.2 ha, 20,345.49 ha, and 14,968.43 ha respectively (Table 4). Conversely, the water 175 body was accounted for 5\% (4383.4 ha) of the total ecosystem of the cities. Specifically, in 1990 176 urban agricultural ecosystem was accounted for more than half of the total area in Hawassa city 177 (56.30\%) and Adama city (53.90\%) followed Bahir Dar (40\%), and Addis Ababa city (39.00\%) 178 respectively. Moreover, the highest urban forest and greenery portion was found in Bahir Dar 179 (43.90\%), followed by Hawassa (20.10\%), Adama (16.40\%), and Addis Ababa (13\%) cities 180 (Figure 4). On the other hand, built up area was accounted for in Addis Ababa city (23.40\%), 181 Adama city (15.70\%), Hawassa (9.80\%) and, Bahir Dar (6.50\%) ascending. In 2000, the total 182 urban agricultural ecosystem was more than two-third of the total cityscapes (41714.77 ha), 183 followed by built-up ecosystem (18637.92 ha), urban forest and greenery (13819.05 ha), and bare 184 land (4310.68 ha). The least ecosystem accounted for by water body (4310.68 ha) (Table 4). 185 Furthermore, the urban agriculture, ecosystem was increased in the Addis Ababa city by $10 \%$, 186 followed by Adama city by $2 \%$, whereas, it was declined by $20 \%$ and $2 \%$ from Bahir Dar and 187 Hawassa cities respectively from 1990 coverage. In the case of the urban built up, the highest 188 agglomeration was found in Addis Ababa and Adama cities by 4\%, followed by Hawassa and 189 Bahir Dar by $2 \%$ for the initial year. In contrast, the urban forest and greenery cover was 190 significantly increased in Bahir Dar by 13\% (2206.7 ha). Conversely, the cover was declined in 191 other cities. Vis-à-vis bare land (open space), the increment was observed in Bahir Dar and 192 Hawassa cities, while the conversion to other types of ecosystem was found in Addis Ababa and 193 Adama cities (Table 3).

194 In 2010, the ecosystem under urban agriculture was covered by 44,698.66 ha of the total 195 cityscapes, afterward, the built-up area and urban forest and greenery accounted for 25, 652.17 ha, $19613,819.05$ ha respectively, while the coverage of water body was declined to 2645.28 ha (Table 
197

198

3). Moreover, Addis Ababa, Hawassa, and Bahir Dar cities were shown the declining trend of urban agricultural ecosystem, while the coverage of the urban agriculture in Adam city had shown increment with the cost of bare land utilization. Regarding, the built-up ecosystem, the largest agglomeration was found in the Addis Ababa city and increased by $14.60 \%$ from 1990, consequently other cities sprawl by $4 \%$ from 1990. In contrast, bare land (open space) and urban forest ecosystems were reduced dramatically and replaced by built up an ecosystem (Table $3 \& 7$ ).

In 2020, the built-up ecosystem accounted a significant proportion in all cities, which accounts for 42298.33ha (more than double that of 1990). Additionally, the built-up ecosystem was augmented by $32.16 \%$ in the Addis Ababa city, $19.64 \%$ in Adama city, Bahir Dar city $(12.72 \%$ ), and by $15.72 \%$ in Hawassa city (Table 3). Besides, the urban agriculture ecosystem was decreased by 8694.26 ha, 499.41 ha, 177.93 ha, and 358.74 ha from Addis Ababa, Adama, Bahir Dar, and Hawas cities in that order (Table 3). Similarly, the urban forest and greenery ecosystem of Addis Ababa and Hawassa cities were declined from 1490.94 ha $(2.77 \%)$ and 507.96 ha $(3.07 \%)$ respectively. However, an increment was observed in Adama and Bahir Dar cities by 448.11ha and 2121.3ha in the past three decades. Besides, the size of water bodies was declined in Adama, Bahir Dar, and Hawas cities by 13.27ha, 108.09ha, and 189.27ha in that order.

Furthermore, Table 4 shows the persistence, gains, losses and net changes of different LULC change accordingly, in Hawassa city, built up has shown a higher persistence value and accounted for $55.56 \%$ followed by urban agriculture ecosystem (30.54\%) while bare land (open space) has shown a higher loss (55\%). Besides, the ecosystem type which persisted the least is urban forest and greenery $(4.8 \%)$ and the ecosystem with least loss is water body $(0.1 \%)$. In Bahir Dar, the urban ecosystem with the highest persistence in urban agriculture, ecosystem (60\%) and that with 
220 the highest loss is urban forest and greenery (70\%). Whereas, built up ecosystem has shown low

221 persistence and losses, but a higher gain percentage. Overall, the results show that 53\% of Bahir

222 Dar city and 48\% of Hawassa city's urban ecosystem remained unchanged over the 1990-2020

223 periods. On the other hand, 47\% of Bahir Dar and 52\% of Hawassa LULC changed during 1990-

224 2020. This indicates that there is a higher change of LULC dynamics in Hawassa city than in Bahir

225 Dar city in the last four decades (Table 3\& 4 and Figure 3).

226 In Addis Ababa city, bare land experienced the least persistent, whereas urban built up were the 227 most persistent ecosystem type (Table 4). The net change in persistence ratio was large for bare 228 land (negative), urban agriculture land (negative), urban forest, and greenery (negative), and built229 up land (positive). Overall, 22841.5 ha of the total ecosystem remains unaffected (Table 4). 230 Moreover, the mass land of the dynamics was shown from urban agriculture to build up, as 231 compared to other land uses. Besides, in Adama city, water bodies experienced the least persistent, 232 whereas urban built up and bare land was the most persistent ecosystem type (Table 4). The net 233 change in persistence ratio was large for water body (negative), urban agriculture land (negative), 234 urban forest and greenery (positive), and built-up land (positive). Overall, 9000.8 ha of the total 235 landscape remains unaffected (Table 4).

237 The spatial distribution LULC dynamics have been scrutinized in four phases, such as 1990 -2000, 238 2000-2010, 2010-2010, and 1990-2020 to explore the changes that took place among the 239 ecosystems (Figure 5). Spatial patterns of ecosystem types in the cityscapes level had shown 240 "urban agriculture $\rightarrow$ urban forest and greenery $\rightarrow$ bare land / open space $\rightarrow$ built up" from urban 241 agricultural and/or forest ecosystem to multi-complex human-made built up an ecosystem (Figure 2423 \& 5). Generally, Bahir Dar and Adama cities were manifested by a mono-nuclei agglomerating 
243 from its urban center, and two secondary nuclei rapidly stretched out after 2010, forming a tri-core

244 urbanization pattern (Figure 5d \& a). Addis Ababa and Hawasa cities have shown a multicore

245 urban agglomeration and new development was sprinkled across all directions from the initial

246 period of urbanization in 2020 (Figure 5b \& c). Particularly, the built-up ecosystem growth of

247 Addis Ababa concerted mainly in the northwest, which was the initial economic zone of the city

248 and then stretched to the southwest parts of the city over 2010, due to the new house development

249 program by the city government.

250

\subsubsection{Extent and rates of urban agglomeration}

251 During the $1990 \mathrm{~s}$, urban agricultural land, and urban forest and greenery were predominant

252 ecosystem types in all cities. Built up, and water bodies accounted for the comparatively small

253 ecosystem (Table 5 \& Figure 4). However, in 2020 the ecosystems were substantially declined

254 concurrent with the significant increases in urbanization throughout the cities. The Annual Increase

255 (AI) of urbanization of Addis Ababa city constantly augments from 1990 to 2020 while, cities like

256 Hawassa, Adama, and, Bahir Dar were declined substantially to 35.69ha, 15.37ha, and 33.20ha in

257 the second period of 2000 -2010 respectively and exponentially augmented between 2010-2020.

258 Moreover, after removing the effect of city size, the annual spreading out rate (AGR) of Addis

259 Ababa city has become $48.89 \%$, and the Bahir Dar city was substantially increased by $71.42 \%$.

260 For all cities, the AGR was the highest during the 2010 - 2020 period of the past three decades.

261 During 2000-2010, Hawassa, Adama and, Bahir Dar cities reached their lowest expansion rate

262 over the past three decades, while the AGR of Bahir Dar was double of the AGR of other cities in

$2632010-2020$ (Table 5). This shows that the dynamics degree of the none built-up area upsurge in

264 built up land in the last 10 years has accelerated, as the result of new housing construction strategies

265 of the country and illegal shifting bare land and urban agriculture to build up. 
Single land use dynamic degree (SLUDD) result shows that a substantial variation between the cities in the past three decades. The highest SLUDD was identified for building up (residential) ecosystem type in Bahir Dar city (8.08\%) followed Addis Ababa, Adama and Hawass cities respectively (Figure 6). On the other hand, urban agriculture declined by $22.99 \%$ in Bahir Dar 271 city, followed Adama and Addis Ababa cities by $19.05 \%$ and 13.64\% respectively. The SLUDD 272 of bare land (open space) was decreased annually by $16.20 \%, 4.56 \%$ and $3.07 \%$ in Addis Ababa, 273 Adama, and Hawass cities and most of the portions were converted to build up an ecosystem. 274 However, the SLUDD value of urban forests and greenery was augmented in Adama and Hawasa 275 cities by $1.65 \%$ and $0.83 \%$ (Figure 5).

276 Conversely, from 1990 to 2020, the ILUDD in Addis Ababa, Bahir Dar, Adama and Hawassa 277 cities were $1.7 \%, 4.17 \%, 2.25 \%$ and, 4.83\% respectively (Table 3). Moreover, the ILUDD was 278 highest in the first period (1990 to 2000) of the study in Bahir Dar, Adama and Hawassa cities. 279 This indicated that cities experienced rapid land use dynamics during this period, with the ILUDD 280 at $6.43 \%, 10.78 \%$, and 7.12\%. While, it was lowest in Addis Ababa city (-0.36\%). After 2000, the 281 ILUDD negatively declined, and it was the lowest from 2000 to 2010 at $4.97 \%$, 3.3\%, and 3.33\% 282 degree in Addis Ababa, Bahir Dar, Adama cities. Besides, comparing the dynamics degree in 283 different LULC types, the conversion rate of built-up ecosystem, water bodies and urban forest 284 and greenery were significantly high, whereas the urban agricultural ecosystem and, bare land 285 (open space) exhibited a reduced trend. The SLUDD of built up of all cities has shown a linear 286 continuously increasing trend from 1990 to 2020 (7.48\%, 4.33\%, 4.16\%, and 8.08\% in Addis 287 Ababa, Bahir Dar, Adama and Hawassa, respectively), while a continuous negative reduction was 288 found in the dynamic in farmland $-1.20 \%,-1.36 \%,-1.18 \%$, and $-0.78 \%$ in Addis Ababa, Bahir 
289 Dar, Adama, and Hawassa, in that order). The spatial transformation in land use dynamics was 290 meticulously associated with urbanization. Between 1990 and 2020, the ILUDD of Hawass city in 291 the central part was considerably higher than in other parts of the city and expand to northeastern 292 and southeastern parts of the city (Figure 8).

293 The high-value ecosystem of ILUDD were found in urban center and then augmented to the north 294 and southwest parts of Addis Ababa city. The northern part was dominated by urban forest and 295 greenery, and the economic development was slower than that of other parts. Adama city that 296 experienced higher ILUDD between the periods 1990 - 2020 was mainly distributed on the 297 northeast and southeast parts also saw rapid land use change, mainly caused by rapid urbanization 298 and expansion of industrial zones. Moreover, Bahir Dar city also saw rapid land use change with 299 higher ILUDD were mainly located in central with the bi-fractured direction of the city (Figure 7).

300 The overall dynamics LUIs of each city in the years 1990 - 2020 were 3.31, 4.82, 5.04, and 3.56, 301 for Addis Ababa, Hawassa, Adama, and Bahir dar cities respectively. In all cities, LUIs growing 302 tendency was found from 1990 to 2000 at a growth rate of $4 \%$. However, the magnitude of the 303 growth rate of LUI was slightly increased with the rate of $15 \%$ in the period of 2000 to 2010 and $30423 \%$ in the period of 2010 to 2020 , and 42\%, and overall augmented by $42 \%$ from 1990 to 2020 305 (Table 5). The results also show that both the land-use intensity and the growth rate continued to 306 increase from 1990 to 2020. The spatial distribution of LUI change during these study periods 307 demonstrated significant consistency with ILUDD in Ethiopia cities (Figure 7). Moreover, cities 308 with rapid economic development in Ethiopia commonly have high input and high output on land, 309 cities with higher LUI increases were mainly located in rapidly developing economic cities. 


\section{Discussion}

\subsection{Comparisons of spatial temporal urban agglomeration and possible drivers}

313 On account of rapid urbanization, large scale rural-urban population migrations, illegal settlement

314 in and around cities and unplanned utilization of urban ecosystem have occurred since 1990, the 315 urban ecosystems configuration and physical morphology are significantly changed in Ethiopia

316 (Larsen et al., 2019; Terfa et al., 2019; Wubie et al., 2020). In addition, rapid economic 317 development, and inconsistence reform, and implement of urban land policy, have led dynamics 318 in land use of cities of Ethiopia (Bulti and Abebe, 2020; Kinfu et al., 2019; Woldegerima et al., 319 2017). Overall, LULC change in urban ecosystem are strongly an anthropogenic-driven process 320 (Das and Das, 2019; Mamat et al., 2018; Peng et al., 2016). Notwithstanding the rapid urban 321 agglomeration of study periods $(1990-2020)$, the spatiotemporal configurations significantly 322 varied among the cities of Bahir Dar, Addis Ababa, Adama, and Hawassa and within the cites. 323 Specifically, the urban ecosystem of Addis Ababa augmented 2.4 times Adama city, and 3.54 and 32411.23 folding of Bahir Dar, and Hawassa cities respectively while that of Adama, Bahir Dar, and 325 Hawassa cities augmented by $2.25 \%, 2.3 \%$ and $3.42 \%$, in that order. Additionally, the direction, 326 pattern and location of urban spreading out in each city have been mainly connected with 327 discrepancies in their illegal settlement in and around cities and unplanned utilization of urban 328 ecosystem, administrative conditions, loopholes of the nation's land policy inter alia, and urban 329 master plans (Admasu et al., 2020; Bulti and Abebe, 2020; Kinfu et al., 2019; Larsen et al., 2019; 330 Wubie et al., 2020).

331 Overall, the present study confirmed that, cities expanding horizontally with different intensity, land 332 use diversity and followed urban agriculture $\rightarrow$ open space $\rightarrow$ urban forest ecosystem $\rightarrow$ build up an 
ecosystem pattern of dynamics. For example, in the case of Addis Ababa city, the presence of the Entoto Mountain in the northern part is limited the outskirt patter to the eastern, southern, and southwest directions (Figure $7 \& 8$ ). While, due to the appearance of lake Tanna and Abayi river the agglomeration of the Bahir Dar city is fractured into two parts and shows unpredicted pattern. Moreover, because of the existence of Lake Hawassa of the western, and Mountain on the south direction, the spreading out of Hawassa city determined to the northeast, east, and southeast parts (Figure7 \& 8). Conversely, in the case of Adama city, because of the occurrence of the mountain along the east direction, the city expands towards north, northeast, and southwest directions (Figure $7 \& 8$ ). The finding is coherent with the recent study in the Addis Ababa city (Larsen et al., 2019), Hawassa city (Kinfu et al., 2019), Adama city (Bulti and Abebe, 2020) and Bahir Dar city (Wubie et al., 2020). While, the priority of driving factors and urban growth pace inversely proportional to each other.

\subsection{Dynamics between land uses}

The result of this study exhibited that significant slice of the landscapes in the in each city exposed to changes in land use and land covers. Built up development, the most outstanding incident, is most related with large-scale deterioration in urban agricultural land. This is maybe happening as the result of secondary land use dynamics and shows a dissimilar trend in that, most studies reported built-up upsurge as expense of urban forest ecosystem (Azagew and Worku, 2020; Fitawok et al., 2020; Gashu and Gebre-Egziabher, 2018; Kinfu et al., 2019; Larsen et al., 2019; Zou and Wang, 2021). Moreover, the lost rate of urban forest and greenery was also high, mainly in ecosystems which are found as fragmented in around urban agricultural ecosystem and border area of the cities. Additionally, the transition of urban agriculture and/ or urban forest change was slightly varying before and after first and second period of study (Table 4). Earlier 1990 to 2000, 
356 urban agricultural/ forest land expansion into built up had fast rate than 2000 to 2010 and had very

357 slow rate that of 2010 to 2020 (Larsen et al., 2019). In the final periods, the devastating increase

358 of ecological land into built up to fulfill the need of housing and urban facilities to the residentials.

359 Overall, urban landscapes transitions are multiple factored and irreversible dynamics.

\section{$360 \quad 4.3$ Urban ecosystem growth and direction}

361 Studying where active urbanization has exist and at what pattern and orientations is very vital for 362 ecological land management and resilience(Larsen et al., 2019; Rimal et al., 2019; Rimal et al., 363 2018). Since, the cities centers are mostly the active hub of socioeconomic and human- ecological 364 land interaction. In the present work, cities expansion started from urban center than rapidly 365 expand to all direction of ecological land (Figure 7 and 8). Additionally, the overall ILUDD 366 analysis shows that all cities have positive expansion rate in all orientation with concentrated to 367 the newly converted ecosystem (Table 3). Moreover, during the first phase of the study the ILUDD 368 was highest in Bahir Dar, Adama and Hawassa cities. This shown that cities experienced rapid 369 urban development, While, it was lowest in Addis Ababa city $(-0.36 \%)$. Later, the ILUDD 370 negatively declined, and the cities center-based orientations of urban growth was observed. This

371 is possibly associated to the decline trend of socio-economic development of the country (Bulti 372 and Abebe, 2020; Kinfu et al., 2019; Larsen et al., 2019; Minta et al., 2018). Besides, LUI resalt 373 shows the degree of human interface on ecological land dynamics because intensity analysis shows 374 the association between socioeconomical factors and the magnitude of impacts of each land use 375 types. Thus, the spatial distribution of LUI change during these study periods demonstrated 376 significant consistency with ILUDD in Ethiopia cities (Figure 7). Moreover, cities with rapid 377 economic development in Ethiopia commonly have high input and high output on ecological land, 
378 cities with higher LUI increases were mainly located in rapidly developing economic cities(Huang

379 et al., 2018; Shao et al., 2020).

\subsection{Implications for planning for sustainable development}

381 Our assessments of the dynamics of LULC change result play significant role for urban ecological 382 land study providing empirical evidences that can work for cities resilient and sustainable 383 development purposes. Additionally, it will serve as baseline to compare and estimate the extent 384 of urban landscapes change, and open discussion during urban policy preparations, and in different 385 features of intervention strategies for green city resilience. Besides, if the one applied the output of 386 this work other areas, it would be filling some gaps of existing literature.

\section{5. Conclusions}

The present study analyzed the dynamics between land and urbanization of four rapidly developing cities of Ethiopia from economical value and spatial point of view. There were substantial dynamics in the urban to built-up ecosystem of each city over the study period, and the overall spatial pattern was followed "urban agriculture $\rightarrow$ urban forest and greenery $\rightarrow$ open space $\rightarrow$

393 built up" from urban agricultural to multi-complex human-dominance ecosystem, with a 394 significant influence on ecological land and ecosystem services provides. Moreover, the direction, 395 pattern and location of urban spreading out in each city have been mainly connected with 396 discrepancies in their illegal settlement in and around cities and unplanned utilization of urban 397 ecosystem, administrative conditions, loopholes of the nation's land policy inter alia, and urban 398 master plans. Notwithstanding, the rapid urban agglomeration of study periods the spatiotemporal configurations significantly varied among the cities. In all cities, better use of existing ecological 

environmental benefits.

402 Abbreviation

403 ESs - ecosystem services

404 ESV- ecosystem serves valuation

405 LUD - land use diversity

406 LUI - land use diversity

407 ILUDD - integrated land use dynamic degree

408 SLM - spatial lag model

409 SEM - spatial error model

410 LULC- land use land cover

411 AA- Addis Ababa

412 BD- Bahir Dar

413 HW- Hawassa

414 AD- Adama

415 AGR- Annual Growth Rate

416

417

418

419

420

421

422

423

424

425

426

427

428

429

430

431

432

433

434

435

436

\section{Declarations}

\section{Acknowledgements}

The authors would like to thank Kotebe Metropolitan University and Addis Ababa University for educational support. The authors also thank USGS (U.S. Geological Survey) for the free data availability and GeoDe and Google Earth pro Developers for the free software

\section{Consent for Publication}

All authors read the manuscript and agreed to publication.

\section{Ethics approval and consent to participate}

There is no ethical conflict.

\section{Authors' contributions}

All authors equally contribute in designed, conducted review, analyzed the data and drafted and writing manuscript. All authors read and approved the final manuscript.

\section{Funding}

This research was not received any financially supported.

\section{Availability of data and materials}

The datasets analyzed during the current study are available from the corresponding author on reasonable request.

\section{Competing interests}

The authors declare that they have no competing interests. 


\section{References}

438 Admasu, W.F., Boerema, A., Nyssen, J., Minale, A.S., Tsegaye, E.A., Van Passel, S. (2020) Uncovering

439 Ecosystem Services of Expropriated Land: The Case of Urban Expansion in Bahir Dar, Northwest Ethiopia.

$440 \quad$ Land 9, 395.

441 Ahmed, D.A., Fawzy, M., Saeed, N.M., Awad, M.A. (2015) Effect of the recent land use on the plant

442 diversity and community structure of Omayed Biosphere Reserve, Egypt. Global Ecology and Conservation $443 \quad 4,26-37$.

444 Azagew, S., Worku, H. (2020) Accessibility of urban green infrastructure in Addis-Ababa city, Ethiopia: 445 current status and future challenge. Environmental Systems Research 9, 1-20.

446 Bhat, P.A., Shafiq, M.u., Mir, A.A., Ahmed, P. (2017) Urban sprawl and its impact on landuse/land cover 447 dynamics of Dehradun City, India. International Journal of Sustainable Built Environment 6, 513-521.

448 Bulti, D.T., Abebe, B.G. (2020) Analyzing the impacts of urbanization on runoff characteristics in Adama 449 city, Ethiopia. SN Applied Sciences 2, 1-13.

450 Chen, L., Pei, S., Liu, X., Qiao, Q., Liu, C. (2021) Mapping and analysing tradeoffs, synergies and losses 451 among multiple ecosystem services across a transitional area in Beijing, China. Ecological Indicators 123, 452107329.

453 Chen, S., Feng, Y., Tong, X., Liu, S., Xie, H., Gao, C., Lei, Z. (2020) Modeling ESV losses caused by 454 urban expansion using cellular automata and geographically weighted regression. Science of The Total 455 Environment 712, 136509.

456 Chen, W., Chi, G., Li, J. (2019) The spatial association of ecosystem services with land use and land cover 457 change at the county level in China, 1995-2015. Science of The Total Environment 669, 459-470. 
Das, M., Das, A. (2019) Dynamics of Urbanization and its impact on Urban Ecosystem Services (UESs): A study of a medium size town of West Bengal, Eastern India. Journal of Urban Management 8, 420-434.

461 temperature changes: A case study of Barrackpore Subdivision, West Bengal, India. Remote Sensing 462 Applications: Society and Environment 19, 100322.

463 Fitawok, M.B., Derudder, B., Minale, A.S., Van Passel, S., Adgo, E., Nyssen, J. (2020) Modeling the 464 Impact of Urbanization on Land-Use Change in Bahir Dar City, Ethiopia: An Integrated Cellular Automata465 Markov Chain Approach. Land 9, 115.

466 Gashaw, T., Tulu, T., Argaw, M., Worqlul, A.W., Tolessa, T., Kindu, M. (2018) Estimating the impacts of 467 land use/land cover changes on Ecosystem Service Values: The case of the Andassa watershed in the Upper 468 Blue Nile basin of Ethiopia. Ecosystem Services 31, 219-228.

469 Gashu, K., Gebre-Egziabher, T. (2018) Spatiotemporal trends of urban land use/land cover and green 470 infrastructure change in two Ethiopian cities: Bahir Dar and Hawassa. Environmental Systems Research 7, 4718.

472 Gebrehiwot, K., Teferi, E., Woldu, Z., Fekadu, M., Desalegn, T., Demissew, S. (2020) Dynamics and 473 drivers of land cover change in the Afroalpine vegetation belt: Abune Yosef mountain range, Northern 474 Ethiopia. Environment, Development and Sustainability, 1-23.

475 Ha, T.V., Tuohy, M., Irwin, M., Tuan, P.V. (2020) Monitoring and mapping rural urbanization and land 476 use changes using Landsat data in the northeast subtropical region of Vietnam. The Egyptian Journal of 477 Remote Sensing and Space Science 23, 11-19. 
478 Hu, S., Chen, L., Li, L., Wang, B., Yuan, L., Cheng, L., Yu, Z., Zhang, T. (2019) Spatiotemporal dynamics

479 of ecosystem service value determined by land-use changes in the urbanization of Anhui Province, China.

480 International journal of environmental research and public health 16, 5104.

481 Huang, A., Xu, Y., Sun, P., Zhou, G., Liu, C., Lu, L., Xiang, Y., Wang, H. (2019) Land use/land cover 482 changes and its impact on ecosystem services in ecologically fragile zone: A case study of Zhangjiakou 483 City, Hebei Province, China. Ecological Indicators 104, 604-614.

484 Huang, B., Huang, J., Gilmore Pontius, R., Tu, Z. (2018) Comparison of Intensity Analysis and the land 485 use dynamic degrees to measure land changes outside versus inside the coastal zone of Longhai, China. 486 Ecological Indicators 89, 336-347.

487 Kindu, M., Schneider, T., Teketay, D., Knoke, T. (2015) Drivers of land use/land cover changes in 488 Munessa-Shashemene landscape of the south-central highlands of Ethiopia. Environmental monitoring and 489 assessment $187,452$.

490 Kindu, M., Schneider, T., Teketay, D., Knoke, T. (2016) Changes of ecosystem service values in response 491 to land use/land cover dynamics in Munessa-Shashemene landscape of the Ethiopian highlands. Science 492 of The Total Environment 547, 137-147.

493 Kinfu, E., Bombeck, H., Nigussie, A., Wegayehu, F. (2019) The genesis of peri-urban Ethiopia: The case 494 of Hawassa city. Journal of Land and Rural Studies 7, 71-95.

495 Larsen, L., Yeshitela, K., Mulatu, T., Seifu, S., Desta, H. (2019) The impact of rapid urbanization and 496 public housing development on urban form and density in Addis Ababa, Ethiopia. Land 8, 66.

497 Li, Z., Sun, Z., Tian, Y., Zhong, J., Yang, W. (2019) Impact of land use/cover change on Yangtze River 498 Delta Urban Agglomeration ecosystem services value: temporal-spatial patterns and cold/hot spots 
ecosystem services value change brought by urbanization. International journal of environmental research

500 and public health 16, 123.

501 Liu, F., Zhang, X., Murayama, Y., Morimoto, T. (2020a) Impacts of Land Cover/Use on the Urban Thermal

502 Environment: A Comparative Study of 10 Megacities in China. Remote Sensing 12, 307.

503 Liu, Y., Hou, X., Li, X., Song, B., Wang, C. (2020b) Assessing and predicting changes in ecosystem service

504 values based on land use/cover change in the Bohai Rim coastal zone. Ecological Indicators 111, 106004.

505 Mamat, A., Halik, Ü., Rouzi, A. (2018) Variations of ecosystem service value in response to land-use 506 change in the Kashgar Region, Northwest China. Sustainability 10, 200.

507 Mekasha, S.T., Suryabhagavan, K., Gebrehiwot, M. (2020) Geo-spatial approach for land-use and land508 cover changes and deforestation mapping: a case study of Ankasha Guagusa, Northwestern, Ethiopia. 509 Tropical Ecology 61, 550-569.

510 Mekuriaw, A., Cherinet, M., Tsegaye, L. (2020) Assessing the impact of land cover changes on selected 511 ecosystem services in upper Suha watershed, Gojjam, Ethiopia. International Journal of River Basin 512 Management, 1-9.

513 Meng, L., Sun, Y., Zhao, S. (2020) Comparing the spatial and temporal dynamics of urban expansion in 514 Guangzhou and Shenzhen from 1975 to 2015: A case study of pioneer cities in China's rapid urbanization. $515 \quad$ Land Use Policy 97, 104753.

516 Minta, M., Kibret, K., Thorne, P., Nigussie, T., Nigatu, L. (2018) Land use and land cover dynamics in 517 Dendi-Jeldu hilly-mountainous areas in the central Ethiopian highlands. Geoderma 314, 27-36.

518 Mohamed, A., Worku, H. (2019) Quantification of the land use/land cover dynamics and the degree of 519 urban growth goodness for sustainable urban land use planning in Addis Ababa and the surrounding Oromia special zone. Journal of Urban Management 8, 145-158. 
521 Peng, W.F., Zhou, J.M., Fan, S.Y., Yang, C.J.J.J.o.t.I.S.o.R.S. (2016) Effects of the land use change on 522 ecosystem service value in Chengdu, western China from 1978 to 2010. 44, 197-206.

523 Rimal, B., Sharma, R., Kunwar, R., Keshtkar, H., Stork, N.E., Rijal, S., Rahman, S.A., Baral, H. (2019)

524 Effects of land use and land cover change on ecosystem services in the Koshi River Basin, Eastern Nepal.

525 Ecosystem Services 38, 100963.

526 Rimal, B., Zhang, L., Keshtkar, H., Haack, B.N., Rijal, S., Zhang, P. (2018) Land use/land cover dynamics 527 and modeling of urban land expansion by the integration of cellular automata and markov chain. ISPRS 528 International Journal of Geo-Information 7, 154.

529 Seto, K.C., Güneralp, B., Hutyra, L.R. (2012) Global forecasts of urban expansion to 2030 and direct 530 impacts on biodiversity and carbon pools. Proceedings of the National Academy of Sciences 109, 1608353116088.

532 Shao, Y., Yuan, X., Ma, C., Ma, R., Ren, Z. (2020) Quantifying the Spatial Association between Land Use 533 Change and Ecosystem Services Value: A Case Study in Xi'an, China. Sustainability 12, 4449.

534 Song, W., Deng, X. (2017) Land-use/land-cover change and ecosystem service provision in China. Science 535 of The Total Environment 576, 705-719.

536 Talukdar, S., Singha, P., Shahfahad, Mahato, S., Praveen, B., Rahman, A. (2020) Dynamics of ecosystem 537 services (ESs) in response to land use land cover (LU/LC) changes in the lower Gangetic plain of India. 538 Ecological Indicators 112, 106121.

539 Temesgen, H., Wu, W., Shi, X., Yirsaw, E., Bekele, B., Kindu, M. (2018) Variation in ecosystem service 540 values in an agroforestry dominated landscape in ethiopia: Implications for land use and conservation 541 policy. Sustainability 10, 1126. 
542 Terfa, B.K., Chen, N., Liu, D., Zhang, X., Niyogi, D. (2019) Urban expansion in Ethiopia from 1987 to

543 2017: Characteristics, spatial patterns, and driving forces. Sustainability 11, 2973.

544 Tolessa, T., Senbeta, F., Kidane, M. (2017) The impact of land use/land cover change on ecosystem services 545 in the central highlands of Ethiopia. Ecosystem Services 23, 47-54.

546 Wangai, P.W., Burkhard, B., Müller, F. (2019) Quantifying and mapping land use changes and regulating 547 ecosystem service potentials in a data-scarce peri-urban region in Kenya. Ecosystems and People 15, 11$548 \quad 32$.

549 Woldegerima, T., Yeshitela, K., Lindley, S. (2017) Characterizing the urban environment through urban 550 morphology types (UMTs) mapping and land surface cover analysis: The case of Addis Ababa, Ethiopia. 551 Urban ecosystems 20, 245-263.

552 Wu, J. (2013) Landscape sustainability science: ecosystem services and human well-being in changing 553 landscapes. Landscape ecology 28, 999-1023.

554 Wubie, A.M., de Vries, W.T., Alemie, B.K. (2020) A Socio-Spatial Analysis of Land Use Dynamics and 555 Process of Land Intervention in the Peri-Urban Areas of Bahir Dar City. Land 9, 445.

556 Ye, Y., Bryan, B.A., Zhang, J.e., Connor, J.D., Chen, L., Qin, Z., He, M. (2018) Changes in land-use and 557 ecosystem services in the Guangzhou-Foshan Metropolitan Area, China from 1990 to 2010: Implications 558 for sustainability under rapid urbanization. Ecological Indicators 93, 930-941.

559 Yohannes, H., Soromessa, T., Argaw, M., Dewan, A. (2020) Changes in landscape composition and 560 configuration in the Beressa watershed, Blue Nile basin of Ethiopian Highlands: historical and future 561 exploration. Heliyon 6, e04859.

562 Zhang, H., Chen, B., Sun, Z., Bao, Z. (2013) Landscape perception and recreation needs in urban green 563 space in Fuyang, Hangzhou, China. Urban Forestry \& Urban Greening 12, 44-52. 
564 Zhang, Y., Liu, Y., Zhang, Y., Liu, Y., Zhang, G., Chen, Y. (2018) On the spatial relationship between 565 ecosystem services and urbanization: A case study in Wuhan, China. Science of The Total Environment 566 637-638, 780-790.

567 Zhao, L., Fan, X. (2020) Effects of Land Use Changes on Ecosystem Service Values: A Case Study in 568 Guilin, China. Polish Journal of Environmental Studies 29.

569 Zorrilla-Miras, P., Palomo, I., Gómez-Baggethun, E., Martín-López, B., Lomas, P.L., Montes, C. (2014)

570 Effects of land-use change on wetland ecosystem services: A case study in the Doñana marshes (SW Spain). 571 Landscape and Urban Planning 122, 160-174.

572 Zou, H., Wang, X.J.S. (2021) Progress and Gaps in Research on Urban Green Space Morphology: A 573 Review. 13, 1202. 




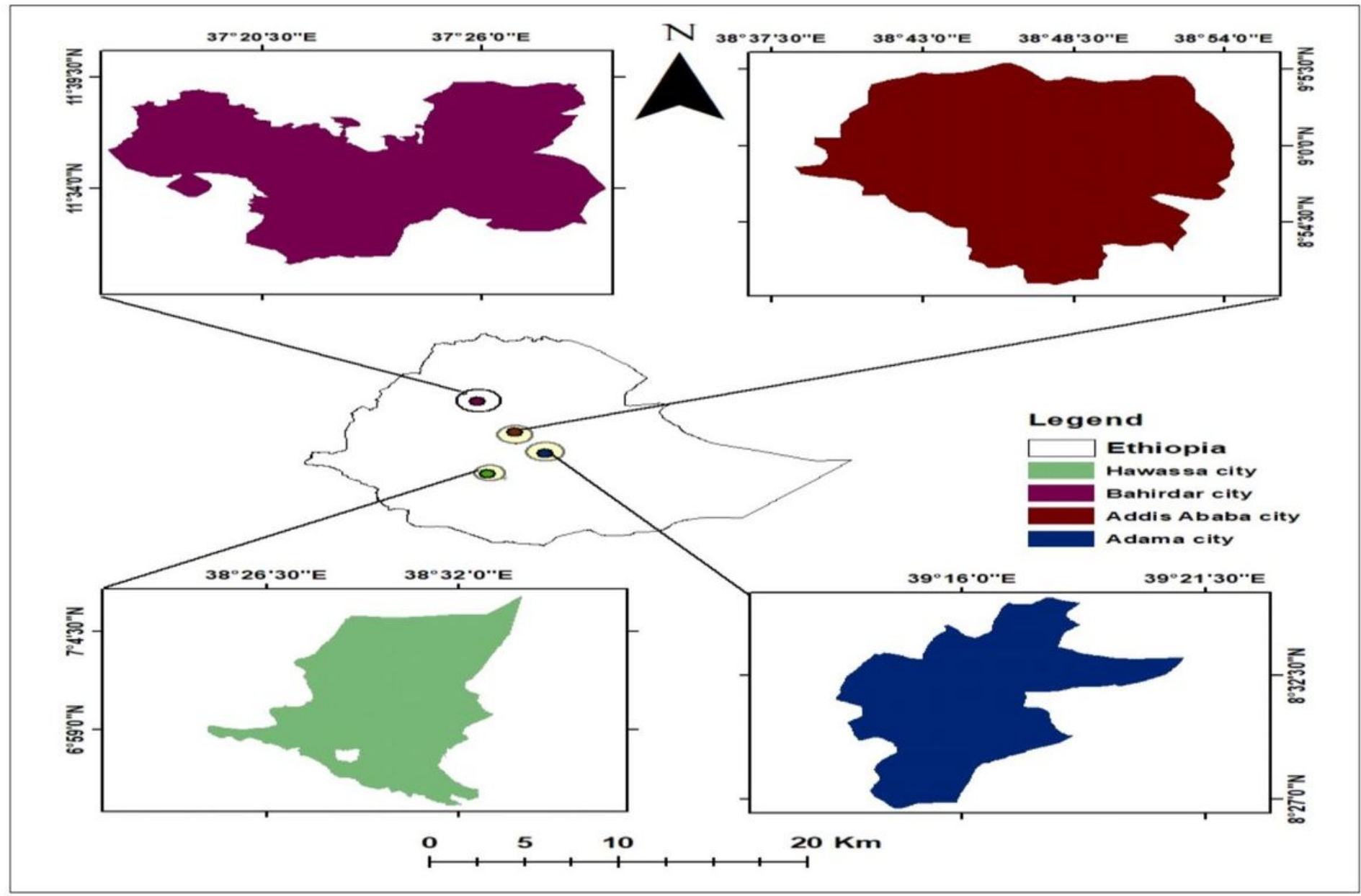

\section{Figure 1}

The location of the areas Note: The designations employed and the presentation of the material on this map do not imply the expression of any opinion whatsoever on the part of Research Square concerning the legal status of any country, territory, city or area or of its authorities, or concerning the delimitation of its frontiers or boundaries. This map has been provided by the authors. 


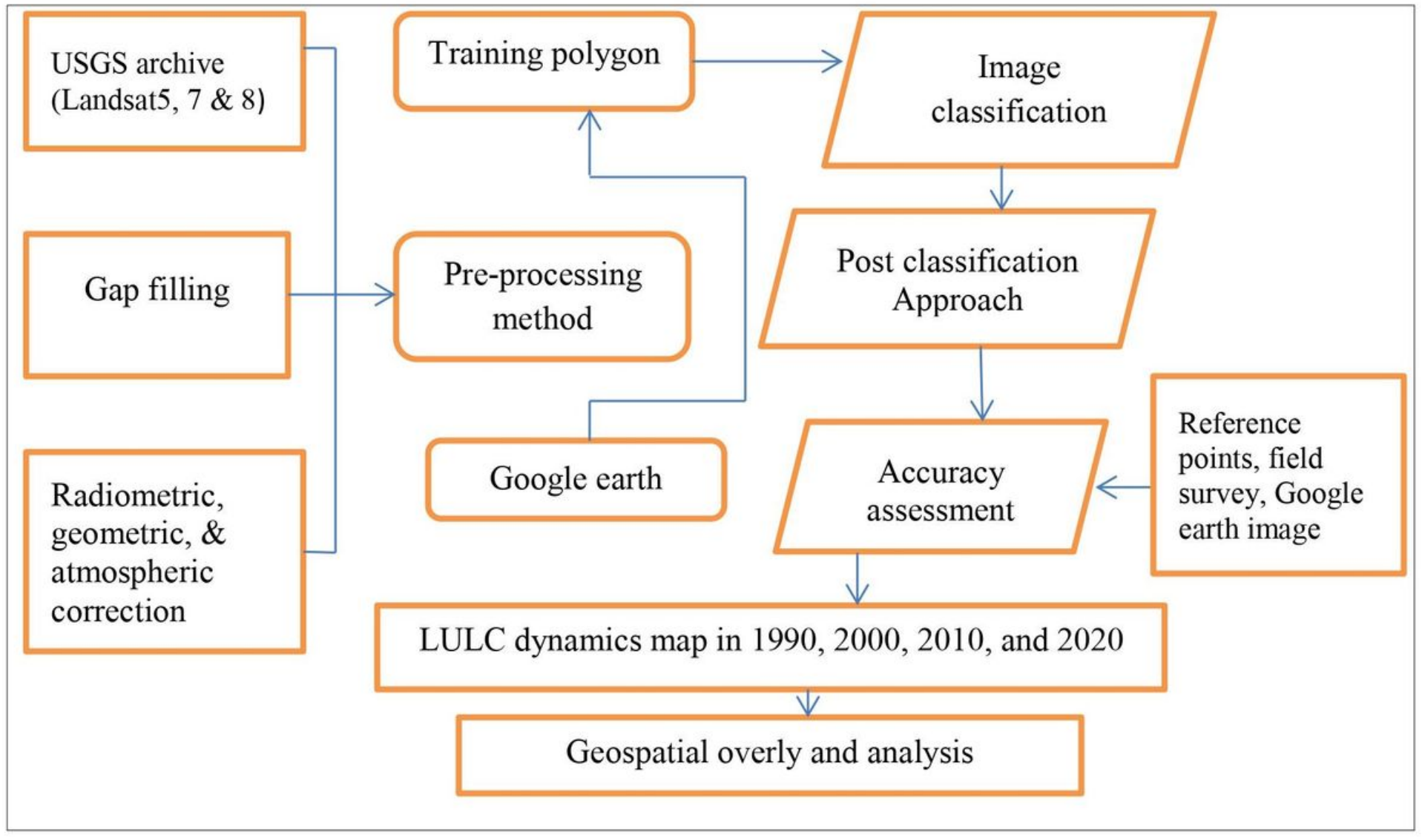

Figure 2

Flow chart of methodological approach 


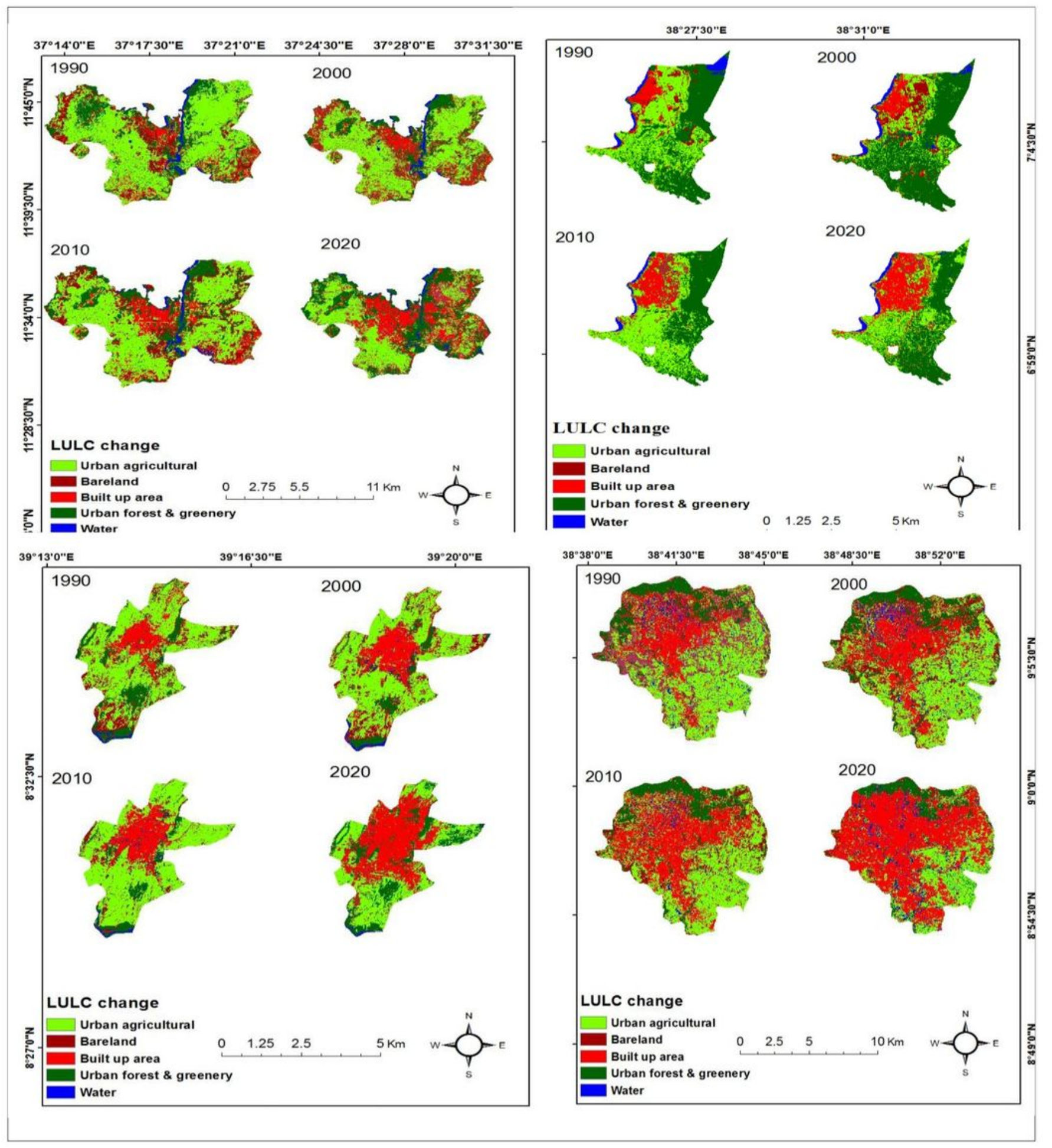

\section{Figure 3}

Spatial distribution of LULC in (a) 1990, (b) 2000, (c) 2010 and (d) 2020 Bahir Dar, Hawassa, Adama and Addis Ababa cities respectively Note: The designations employed and the presentation of the material on this map do not imply the expression of any opinion whatsoever on the part of Research Square concerning the legal status of any country, territory, city or area or of its authorities, or concerning the delimitation of its frontiers or boundaries. This map has been provided by the authors. 


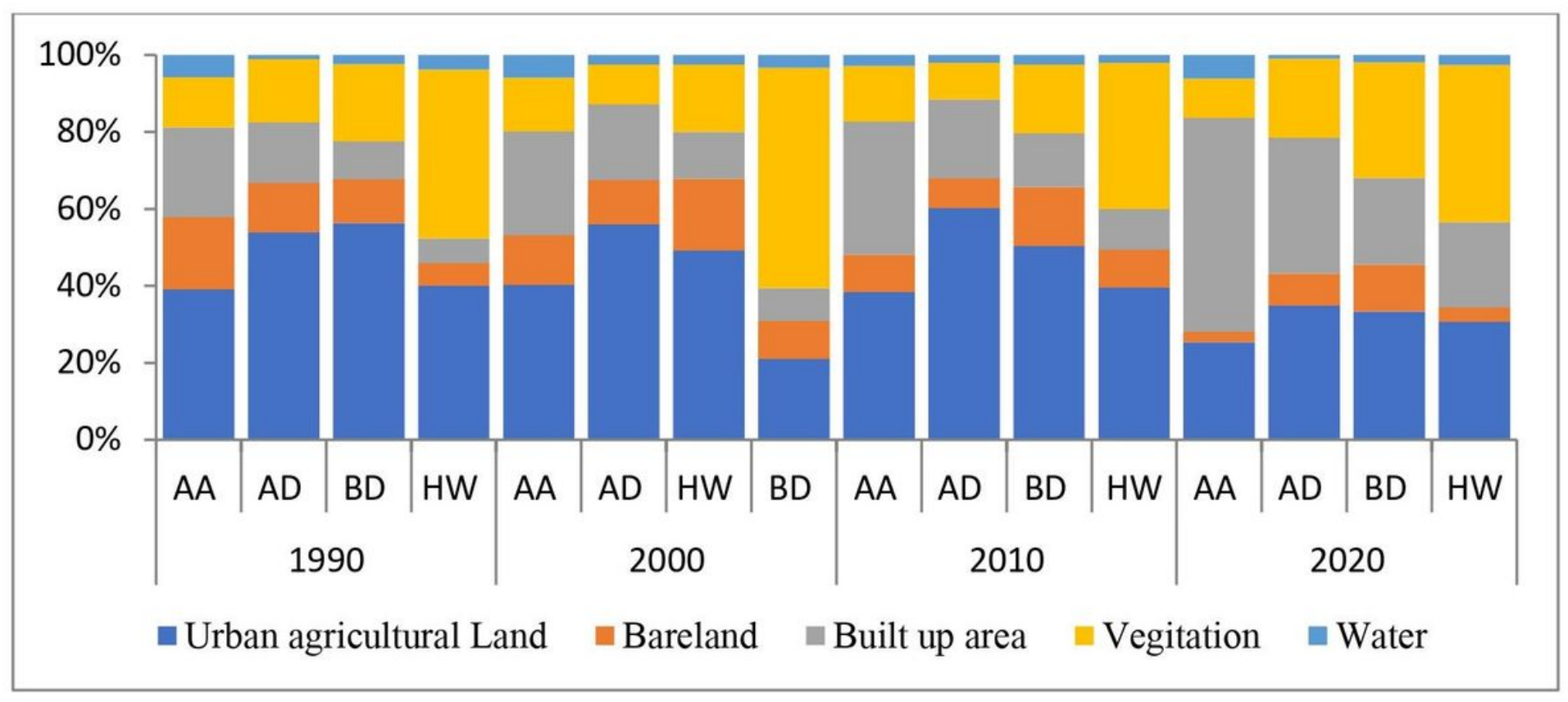

Figure 4

Size and percentage contribution of each of five ecosystem types in each city and the total study area 

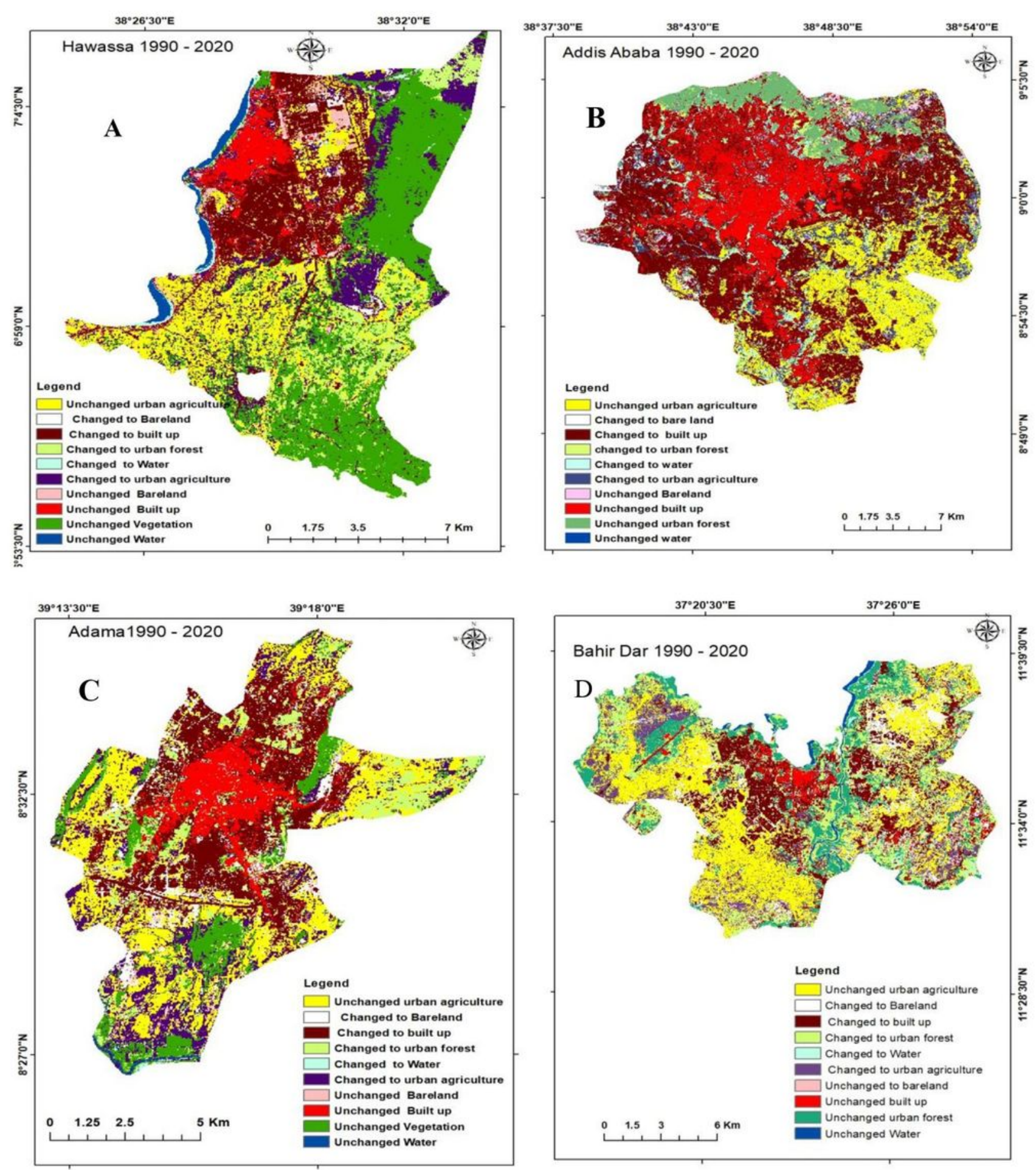

\section{Figure 5}

Spatial patterns and LULC change transition of cities from 1990 to 2020 Note: The designations employed and the presentation of the material on this map do not imply the expression of any opinion whatsoever on the part of Research Square concerning the legal status of any country, territory, city or area or of its authorities, or concerning the delimitation of its frontiers or boundaries. This map has been provided by the authors. 


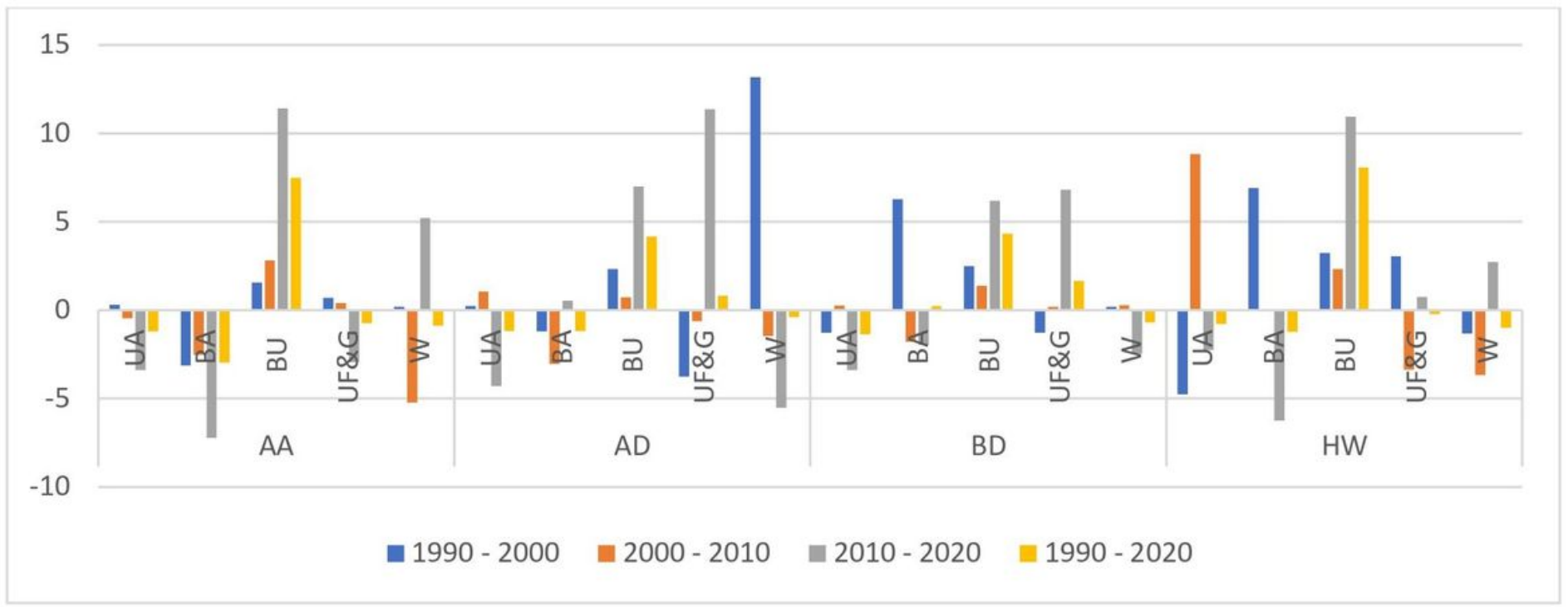

Figure 6

The percentage of the SLUDD of LULC in cities *AA: Addis Ababa, AD: Adama, BD: Bahirdar and HW: Hawassa, UA: Urban agriculture, BL: bare land, BU: built up, W: water, and UF\&G: urban forest \& greenery 

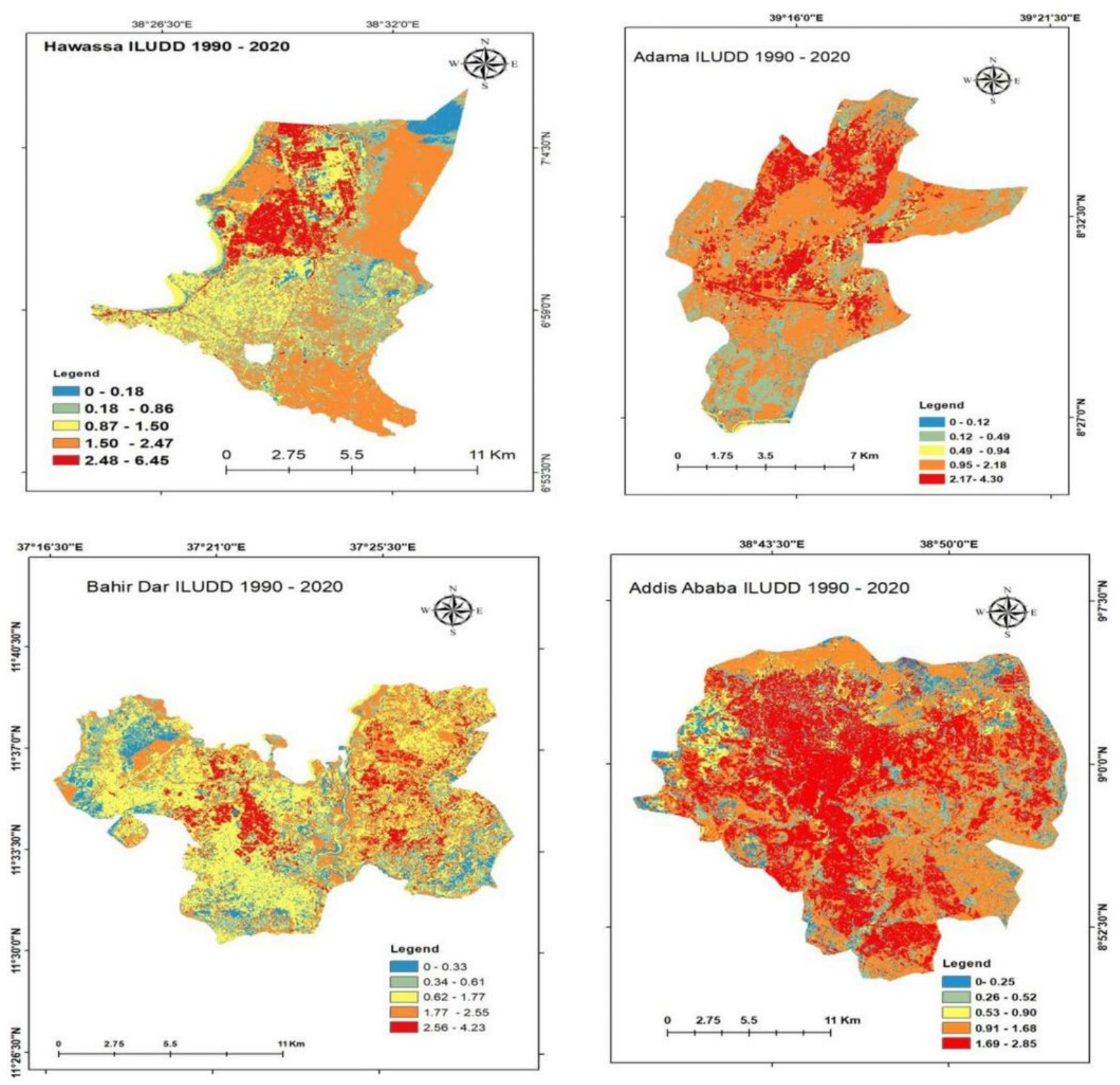

\section{Figure 7}

The ILUDD of cities from 1990 to 2020 Note: The designations employed and the presentation of the material on this map do not imply the expression of any opinion whatsoever on the part of Research Square concerning the legal status of any country, territory, city or area or of its authorities, or concerning the delimitation of its frontiers or boundaries. This map has been provided by the authors. 

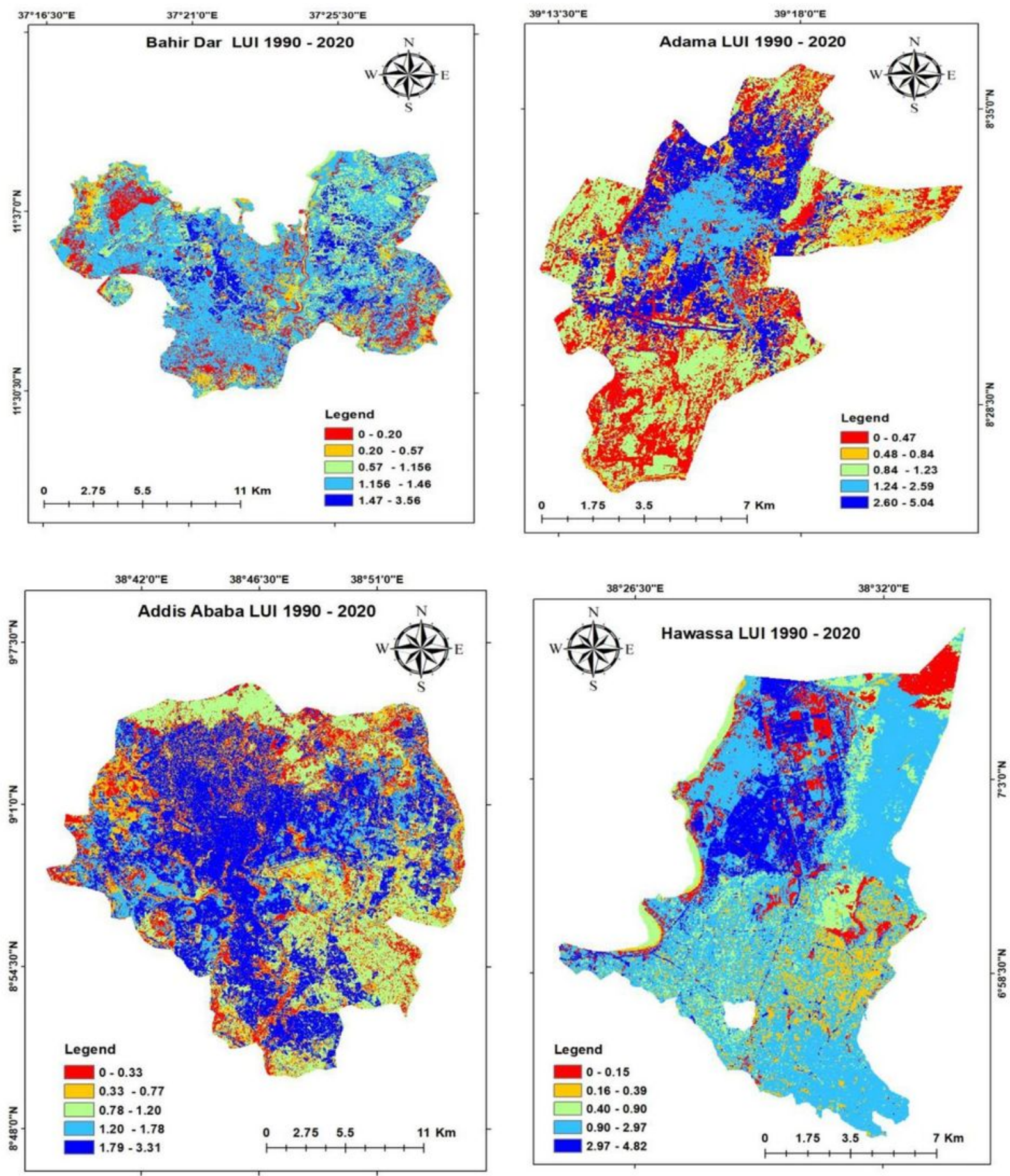

\section{Figure 8}

The LUI of cities from1990 to 2020 Note: The designations employed and the presentation of the material on this map do not imply the expression of any opinion whatsoever on the part of Research Square concerning the legal status of any country, territory, city or area or of its authorities, or concerning the delimitation of its frontiers or boundaries. This map has been provided by the authors. 